\title{
Hardness and Microstructure of Internally Oxidized Silver Alloys*
}

\author{
B. C. Prorok, J. H. Park, K. C. Goretta, and U. Balachandran \\ Energy Technology Division \\ Argonne National Laboratory \\ 9700 S. Cass Avenue, Argonne, IIL 60439
}

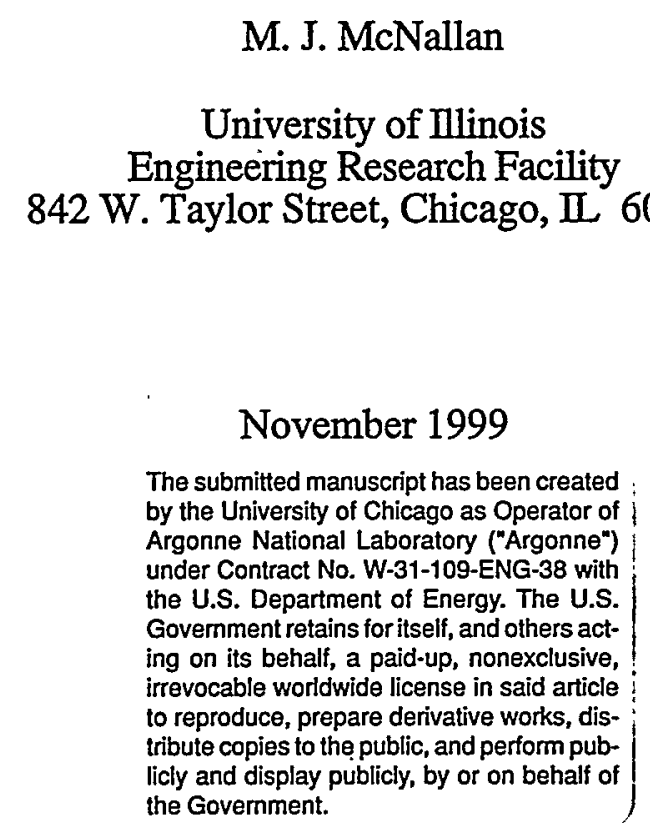

Paper presented at 16th Annual Conference on Magnet Technology, Ponte Vedra Beach, FL, September 27-October 2, 1999. To be published in IEEE.

*Work supported by the U.S. Department of Energy (DOE), Office of Energy Efficiency and Renewable Energy, as part of a DOE program to develop electric power technology, under Contract W-31-109-Eng-38. 


\section{DISCLAIMER}

This report was prepared as an account of work sponsored by an agency of the United States Government. Neither the United States Government nor any agency thereof, nor any of their employees, make any warranty, express or implied, or assumes any legal liability or responsibility for the accuracy, completeness, or usefulness of any information, apparatus, product, or process disclosed, or represents that its use would not infringe privately owned rights. Reference herein to any specific commercial product, process, or service by trade name, trademark, manufacturer, or otherwise does not necessarily constitute or imply its endorsement, recommendation, or favoring by the United States Government or any agency thereof. The views and opinions of authors expressed herein do not necessarily state or reflect those of the United States Government or any agency thereof. 


\section{DISCLAIMER}

Portions of this document may be illegible in electronic image products. Images are produced from the best available original document. 


\title{
Hardness and Microstructure of Internally Oxidized Silver Alloys
}

\author{
B. C. Prorok, J. H. Park, K. C. Goretta, and U. Balachandran \\ Energy Technology Division, Argonne National Laboratory, Argonne, IL 60439 \\ M. J. McNallan \\ University of Illinois at Chicago, Chicago, IL 60607
}

Abstract--Alloys of $\mathrm{Ag}, \mathrm{Ag} / 1.12$ at.\% $\mathrm{Mg}$, and $\mathrm{Ag} / 0.25$ at.\% $\mathrm{Mg}-0.25$ at.\% Ni were internally oxidized at 450 to $825^{\circ} \mathrm{C}$ and their hardnesses and microstructures were observed. Microhardness profiles showed that hardness was high near the surface and decreased with depth into the sample. Microstructures contained regions of small and large grains, where region sizes were dependent on treatment temperature. Transitions between small- and large-grained regions were abrupt. Treatments at higher temperatures failed to alter grain structure, indicating that $\mathrm{Mg}-\mathrm{O}$ clusters had indeed pinned the grain boundaries. Clustering was shown to affect the hardness of oxidized alloys, not only by inhibiting grain growth, but also by inhibiting dislocation motion.

Index terms-- Internal Oxidation, Ag Alloys, High-Temperature Superconductors 


\section{INTRODUCTION}

Dispersion-hardened $\mathrm{Ag}$ alloys are being developed as sheaths for high-temperature superconductor wires and tapes [1-5]. Increased strength over that of pure $\mathrm{Ag}$ is needed for strain tolerance and reliable performance in high magnetic fields. Hardening of these $\mathrm{Ag}$ alloys is generally accomplished by internally oxidizing solute species such as $\mathrm{Mg}[1,3,5]$ or Ni [2]. Oxidation of such alloys is a complex process in which several events occur simultaneously: $\mathrm{O}$ diffuses in from the environment; the solutes diffuse toward the $\mathrm{O}$ source; the solutes oxidize to form, first, O-rich clusters and, later, discrete oxide precipitates; and the alloy's grains grow, but this growth is impeded once sufficiently large and numerous solute/O particles form. Each of these events affects the resulting mechanical properties of the alloy.

Mechanical and microstructural studies of $\mathrm{Ag}$ alloys that contain up to 4.4 at.\% $\mathrm{Mg}$ have confirmed that substantial strengthening occurs through oxidation, with a corresponding decrease in ductility [6-9]. For sheathed superconductors, oxidation will occur after mechanical deformation, and thus reduction of ductility should not be a concern [1-5]; attainment of maximum strength in the sheath is the primary objective. The strength of the sheath will depend primarily on its composition and heat treatment.

The goal of this work is to identify optimal heat treatments for hardening two $\mathrm{Ag}$ alloys that may be used as sheaths for (Bi2223) superconductors $\mathrm{Ag} / 1.12$ at.\% $\mathrm{Mg}$ $(\mathrm{AgMg})$ and $\mathrm{Ag} / 0.25$ at.\% $\mathrm{Mg}-0.25$ at.\% $\mathrm{Ni}(\mathrm{AgMgNi})[1,2,6]$. The extent and distribution of strength within oxidized test specimens was assessed by microhardness measurements, which are correlated with microstructural development. 


\section{EXPerimental Procedures}

Square coupons ( $\leq 0.5 \mathrm{~g}$ and $0.4 \mathrm{~mm}$ thick) of $99.9 \% \mathrm{Ag}, \mathrm{AgMg}$, and $\mathrm{AgMgNi}$ were prepared from cold-rolled sheets. Coupons were heat treated in flowing $8 \% \mathrm{O}_{2}$ at 450 to $825^{\circ} \mathrm{C}$. Treatment times ranged from 2 to $100 \mathrm{~h}$, depending on time required to reach saturation of dissolved $\mathrm{O}$. All samples were given a secondary heat treatment at $825^{\circ} \mathrm{C}$ in flowing $8 \% \mathrm{O}_{2}$ for $50 \mathrm{~h}$ to simulate actual heat treatments of composite superconductor tapes [5]. Cross-sectional Knoop hardness profiles were obtained for the heat-treated coupons. The microstructures of polished surfaces were examined by scanning electron microscopy (SEM).

\section{RESULTS AND Discussion}

Figure 1 shows microhardness profiles of cross sections of $\mathrm{AgMg}$ and $\mathrm{AgMgNi}$ alloys treated at 450 to $825^{\circ} \mathrm{C}$ in flowing $8 \% \mathrm{O}_{2}$. For all samples, changes in hardness were a function of depth. Hardness near the surface was high and decreased toward the center. For the $\mathrm{AgMg}$ alloy, a treatment temperature of $700^{\circ} \mathrm{C}$ yielded the profile with the highest hardnesses. For the AgMgNi alloy, temperatures between 450 and $700^{\circ} \mathrm{C}$ all yielded profiles of similar hardness. These hardnesses were two to three times higher then those of annealed 99.9Ag, $\mathrm{H}_{\mathrm{k}}(\mathrm{Ag})=48 \mathrm{~kg} / \mathrm{mm}^{2}$. The $\mathrm{AgMgNi}$ alloy yielded hardnesses that were $\approx 13 \%$ lower than those of the $\mathrm{AgMg}$ alloy. The difference between the alloys is attributed to the lower total concentration of solute in the AgMgNi.

After receiving a second heat treatment at $825^{\circ} \mathrm{C}$ in flowing $8 \% \mathrm{O}_{2}$ for $50 \mathrm{~h}$, some samples showed marginal increases in hardness, with a few exhibiting a marked increase. In the AgMg alloy (Fig. 2a), large increases in hardness occurred in both the 450 and $600^{\circ} \mathrm{C}$ samples, with the $600^{\circ} \mathrm{C}$ first heating yielding the highest hardness profile. The 
AgMgNi exhibited only marginal increases of hardness in the 700 and $825^{\circ} \mathrm{C}$ samples (Fig. 2b). For $\mathrm{AgMgNi}$, the $700^{\circ} \mathrm{C}$ sample yielded the highest hardness profile.

Observations of microstructure may offer explanations for these mechanical properties. SEM photomicrographs of etched cross sections of both alloys after the first heat treatment revealed remarkable differences in grain structure among the various heat-treatment temperatures (Fig. 3). In $\mathrm{AgMg}$ alloy at $450^{\circ} \mathrm{C}$, grain size was small and relatively uniform across the sample. At $500^{\circ} \mathrm{C}$, a region with grains that were considerably larger emerged in the centers of the samples. The large-grained region increased in size for the 600,700 , and $825^{\circ} \mathrm{C}$ samples.

This contrast is believed to be the result of differences in the rate of grain growth and $\mathrm{O}$ transport at the various temperatures. At $450^{\circ} \mathrm{C}$, the rate of $\mathrm{O}$ transport was relatively slow, but so was the rate of grain growth. Here, $\mathrm{O}$ diffused to the center of the sample and formed grain-growth-inhibiting $\mathrm{Mg}-\mathrm{O}$ clusters $[10,11]$ before significant grain growth could occur. As temperature increased, so did the rates of both processes. At $500^{\circ} \mathrm{C}$ and above, significant grain growth occurred in the interior before $O$ could penetrate and form $\mathrm{Mg}-\mathrm{O}$ clusters. In the 600,700 , and $825^{\circ} \mathrm{C}$ samples, the regions composed of small grains and large grains were nearly identical in size. This equality is probably a consequence of all samples having been processed at the same heating rate of $120^{\circ} \mathrm{C} / \mathrm{h}$. Oxygen diffusion and grain growth are both kinetic processes. At some temperature between $\approx 500$ and $600^{\circ} \mathrm{C}$, the dominance of grain growth in controlling microstructure was established. The kinetics of oxidation will be reported separately [11].

In the AgMgNi alloy, grain size was relatively small at all temperatures (Fig. 3b). This finding suggests that at the chosen heating rate, $O$ diffusion was the dominant 
microstructure controlling factor. This alloy did not exhibit the regions of differing grain size that were exhibited by the AgMg alloy. Instead, grain size was small near the surface and gradually increased toward the interior.

All samples of both alloys were given a second treatment at $825^{\circ} \mathrm{C}$ in flowing $8 \% \mathrm{O}_{2}$ for $50 \mathrm{~h}$ to simulate the actual treatment to a composite Bi2223 superconductor tape. The grain structures of both alloys after such treatment did not change (Fig. 4), suggesting that solute-O clusters were present and indeed pinned the grain boundaries.

There is a question as to whether $\mathrm{Mg}-\mathrm{O}$ clusters or grain size governs the mechanical properties of these internally oxidized alloys. Clustering certainly plays a role in determining grain size, but the extent to which clusters impede dislocation motion has yet to be established. If we superimpose the grain-size distributions and microhardness profiles we can examine the relationship between the two. Figure 5 is a hardness profile for the $700^{\circ} \mathrm{C}$ sample of the $\mathrm{AgMg}$ alloy; it includes hardness data from both heat treatments. After the first treatment, the transition from the small- to the large-grained region appears to be accompanied by a decrease in hardness with increasing grain size, in accordance with the Hall-Petch relation [12],

$$
\sigma \propto \mathrm{D}^{-1 / 2}
$$

where $\sigma$ is the strength (or hardness) and $D$ is the average grain size.

However, the decreases in hardness are not as abrupt as the change in grain size, which suggests that the distribution of solute-O clusters also plays a role in hardening of the 
alloy. The Hall-Petch relation predicts that based on grain size alone, the hardness in the large-grained region should have decreased to $\approx 110 \mathrm{~kg} / \mathrm{mm}^{2}$ rather than to $\approx 130 \mathrm{~kg} / \mathrm{mm}^{2}$.

After the second heat treatment, the hardness profile flattens and reaches an approximately constant hardness in the large-grained region with slightly increased hardness at the surface in the small-grained region. Here, hardness remains nearly uniform across the boundary between grain sizes, suggesting that clustering becomes more influential than grain size in determining hardness.

From the standpoint of strengthening a composite superconductor sheath, these studies indicate the following: (a) AgMg was significantly harder than AgMgNi. (b) To obtain maximum strength in an $\mathrm{AgMg}$ sheath, a two-step oxidation heat treatment should be employed; oxidation at $\approx 450-600^{\circ} \mathrm{C}$ should be followed by heating at $\approx 825^{\circ} \mathrm{C}$ to sinter the Bi2223 superconductor. (c) For $\mathrm{AgMgNi}$, initial oxidation should be at $\approx 700^{\circ} \mathrm{C}$, followed by long-term heating at $\approx 825^{\circ} \mathrm{C}$. (d) Grain size did not change after the initial oxidation heat treatment, but hardness profiles were affected by the second heat treatment; probably because of solute-cluster rearrangement.

\section{Conclusions}

Internal oxidation of $\mathrm{Ag}$ alloys that contain $\mathrm{Mg}$ and $\mathrm{Ni}$ is complicated and highly dependent on processing temperature. The presence of $\mathrm{Mg}-\mathrm{O}$ significantly affects hardness and microstructure; the hardening is effected by impeding dislocation motion. The hardnesses of oxidized AgMg and AgMgNi alloys were significantly higher than that of Ag. The alloys exhibited profiles of high hardness near the surface and lower hardness toward the sample interior. Microstructures showed regions of large and small grain size, 
with a steep transition from one region to the other. Hardness was higher in the smallgrained regions and lower in the larger-grained regions, in accordance with the Hall-Petch relation. However, this transition in hardness was not as abrupt as the change in grain size, suggesting the effect of another factor on hardness. After the second heat treatment, hardness was more uniform across the grain-size transition, indicating lessening of the influence of grain size on hardness.

\section{ACKNOWLEDGMENTS}

We thank Prof. J. Schwartz of Florida State University for providing the AgMg alloy. Work supported by the U.S. Department of Energy (DOE), Office of Energy Efficiency and Renewable Energy, as part of a DOE program to develop electric power technology, under Contract W-31-109-Eng-38.

\section{REFERENCES}

1. J. Tenbrink, M. Wilhelm, K. Heine, and H. Krauth, Development of technical high- $T_{c}$ superconductor wires and tapes, IEEE Trans. Appl. Supercond. 3, 1123-1126 (1993).

2. J. A. Parrell, S. E. Dorris, and D. C. Larbalestier, The effect of sheath material and deformation method on the oxide core density, filament uniformity, and critical current density of $(\mathrm{Bi}, \mathrm{Pb})_{2} \mathrm{Sr}_{2} \mathrm{Ca}_{2} \mathrm{Cu}_{3} \mathrm{O}_{\mathrm{x}}$ tapes, Adv. Cryo. Eng. 40, 193-200 (1994). 
3. J. Schwartz, J. K. Heuer, K. C. Goretta, R. B. Poeppel, J. Guo, and G. W. Raban Jr., High-temperature mechanical properties and high-strength sheaths for powder-in-tube tapes, Appl. Supercond. 2, 271-280 (1994).

4. J. Guo, J. A. Lewis, K. C. Goretta, and J. Schwartz, Properties and chemical stability of hot-rolled Ag-Sheathed $\mathrm{Bi}_{2} \mathrm{Sr}_{2} \mathrm{Ca}_{0.64} \mathrm{Cu}_{1.64} \mathrm{O}_{x}$ powder-in-tube tapes, J. Appl. Phys. $78,4596-4607$ (1995).

5. W. Goldacker, E. Mossang, M. Quilitz, and M. Rikel, On the phase formation in Ag and AgMg sheathed BSCCO (2223) tapes, IEEE Trans. Appl. Supercond. 7, 14071410 (1997).

6. D. L. Douglas, B. Zhu, and F. Gesmundo, Internal-oxide-band formation during oxidation of Ag-Mg alloys, Oxid. Met. 38, 365-371 (1992).

7. L. Charrin, A. Combe, F. Cabane, and J. Cabane, Evidence for the formation of substoichiometric species during internal oxidation of Ag-Mg alloys, Oxid. Met. 40, 483-497 (1993).

8. B. M. Semega, L. Charrin, A. Combe, and J. Aride, Evolution of the structure of internal oxidation of Ag-0.4 at.\% Mg alloy, Philos. Mag. 66, 1139-1144 (1992).

9. K. C. Goretta, J. L. Routbort, J. P. Carroll, R. L. Thayer, J. Wolfenstine, J. Kessler, and J. Schwartz, Deformation of Ag/1.2 at.\% Mg, Physica C 265, 201-206 (1996).

10. L. S. Darken, Some observations on atoms and imperfections, Trans. ASM 54, $612-$ $616(1961)$ 
11. J. H. Park, B. C. Prorok, K. C. Goretta, U. Balachandran, and M. J. McNallan, High temperature internal oxidation of $\mathrm{AgMg}$ and $\mathrm{AgMgNi}$ alloys, 196th Electrochemical Society Meeting, Honolulu, Oct. 17-22, 1999.

12. N. J. Petch, The cleavage strength of polycryatals, J. Iron Steel Inst. 173, 281-287 (1953). 
(a)

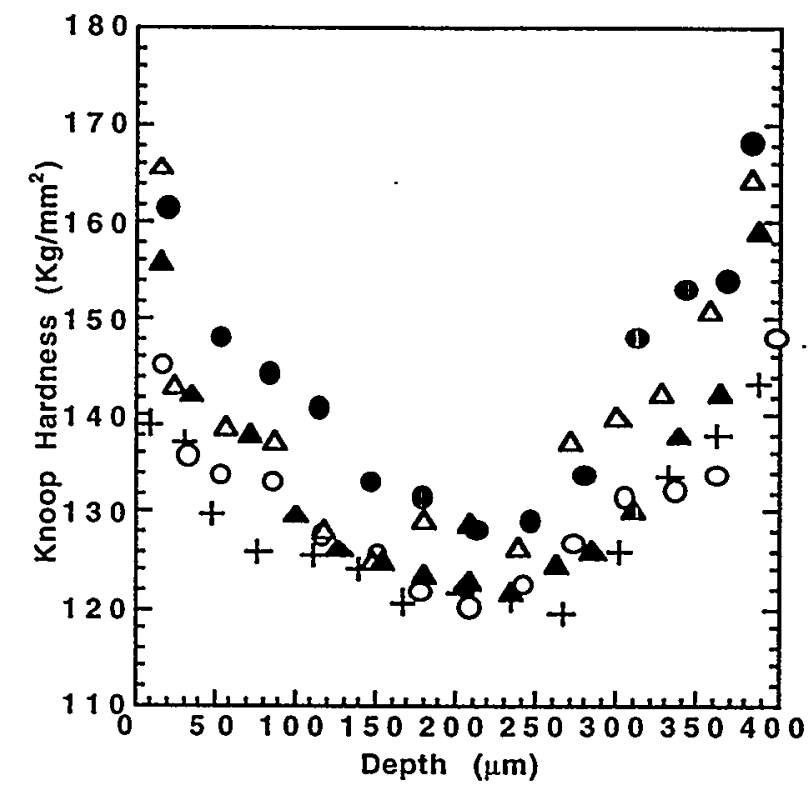

(b)

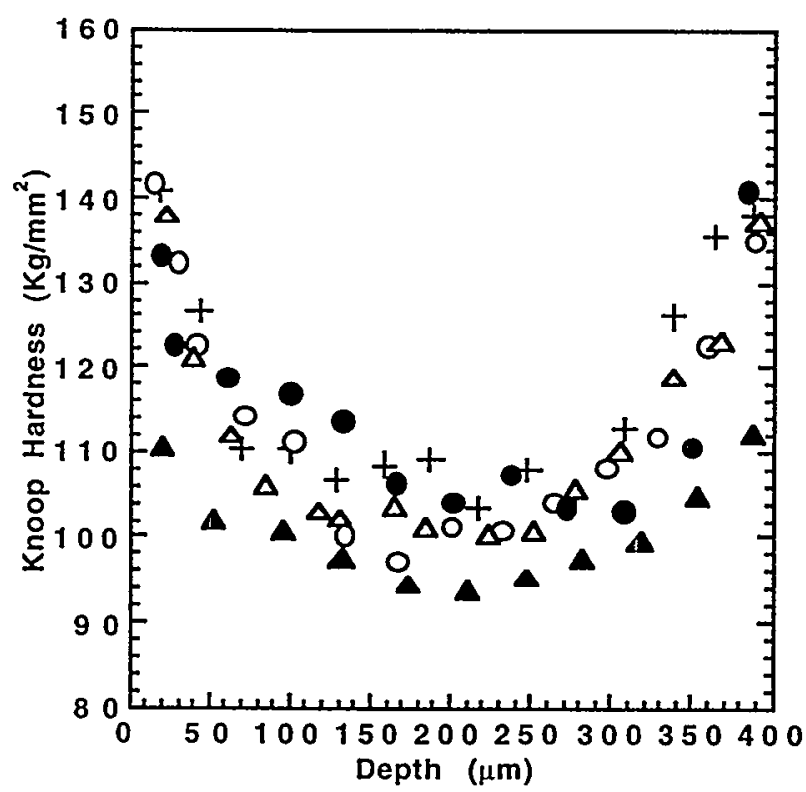

Figure 1. Microhardness profiles of (a) $\mathrm{AgMg}$ and (b) $\mathrm{AgMgNi}$ after first heat treatment at: $450(+), 500(\bigcirc), 600(\Delta), 700(\bullet)$, and $825^{\circ} \mathrm{C}(\mathbf{\Lambda})$. 
(a)

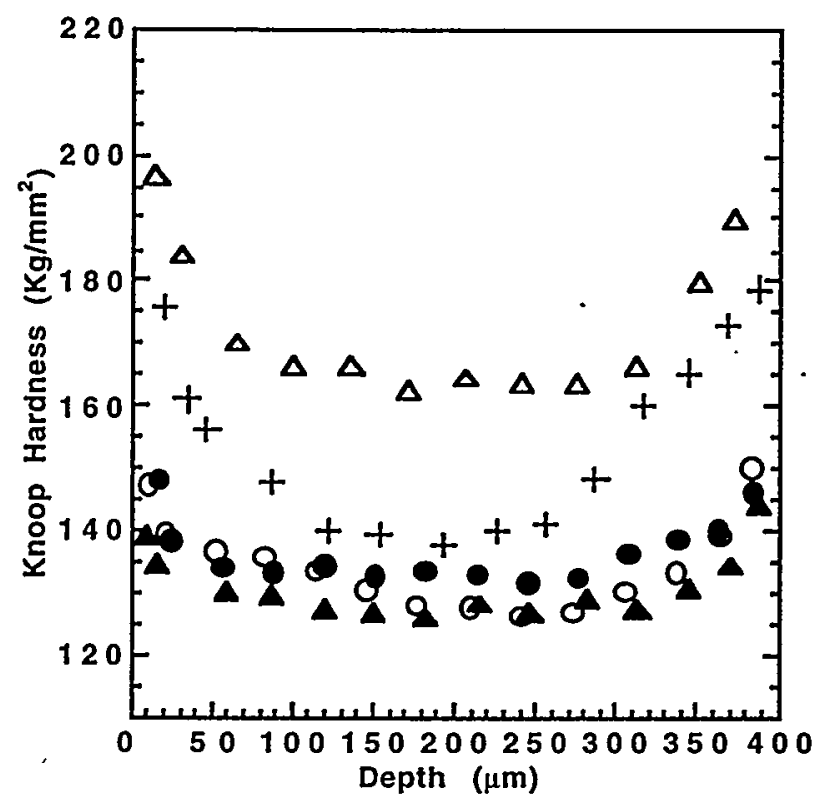

(b)

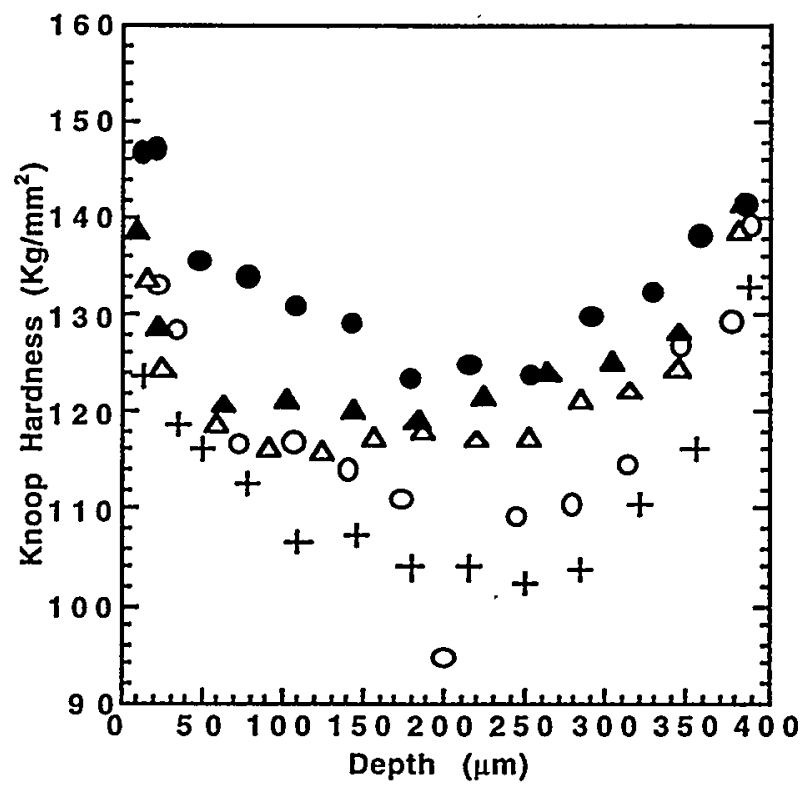

Figure 2. Microhardness profiles of alloys (a) AgMg and (b) AgMgNi after second heat treatment at $825^{\circ} \mathrm{C}: 450(+), 500(\bigcirc), 600(\Delta), 700(\Theta)$, and $825^{\circ} \mathrm{C}(\Delta)$. 

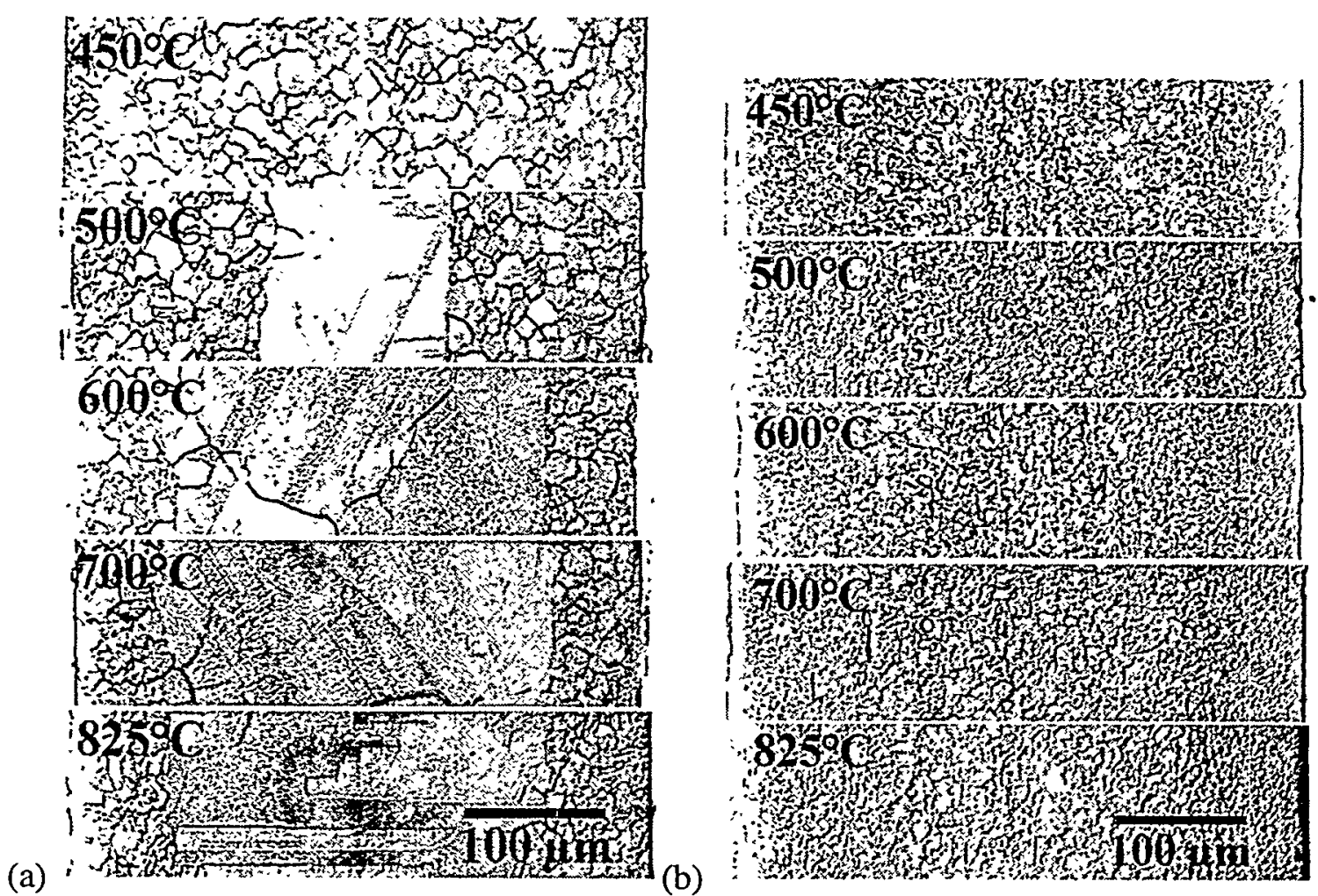

Figure 3. Scanning electron photomicrographs of etched (a) AgMg and (b) AgMgNi after first heat treatment.
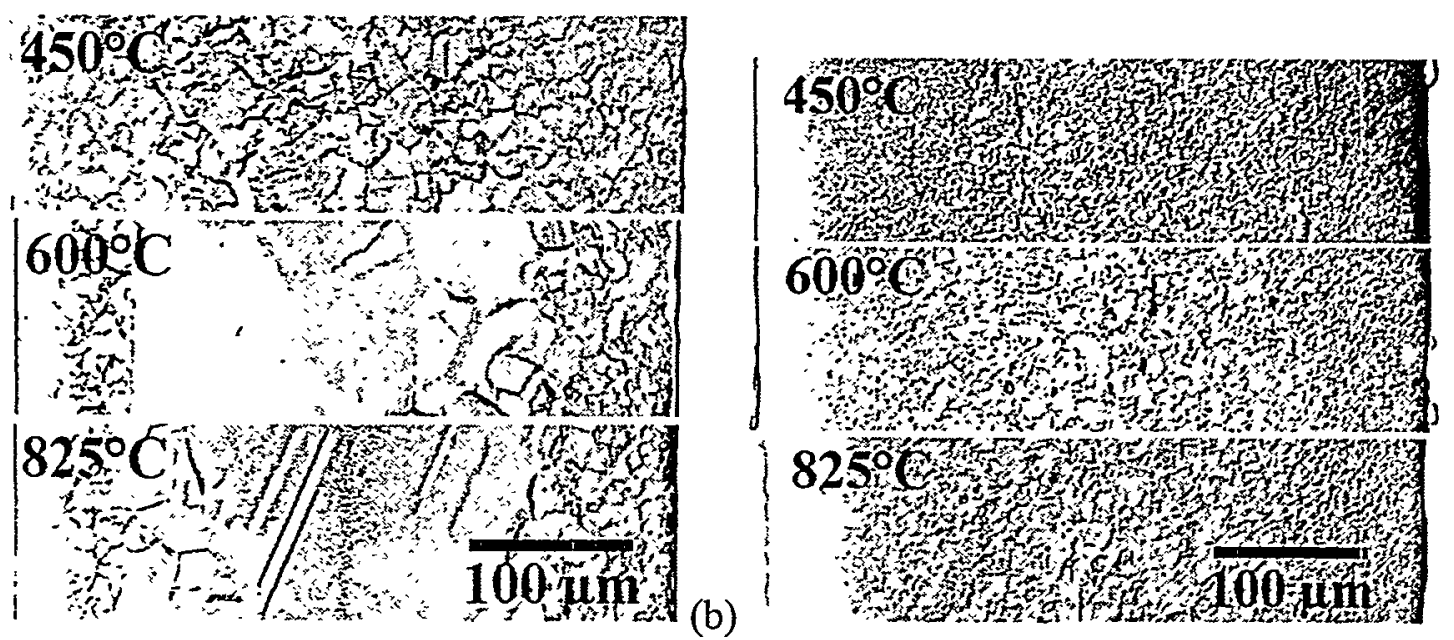

Figure 4. Scanning electron photomicrographs of etched (a) AgMg and (b) AgMgNi after second heat treatment. 


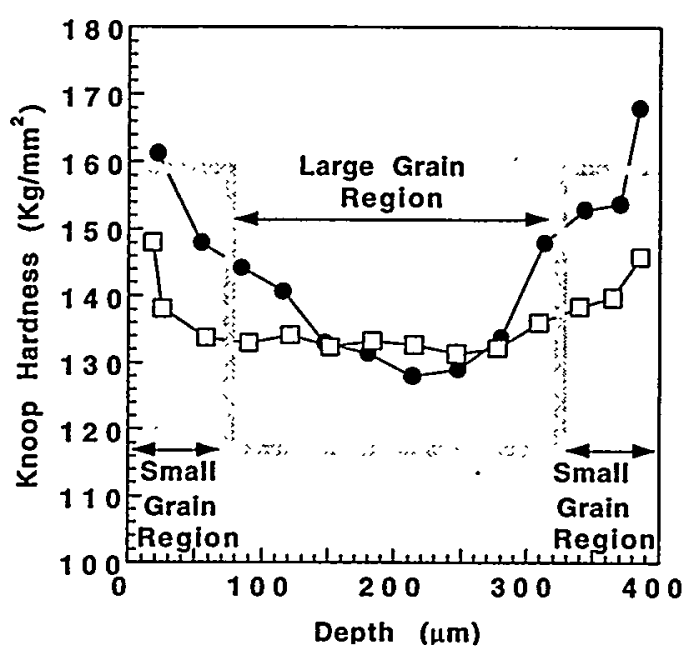

Figure 5. Relationship of grain size regions to hardness profile of AgMg treated in $8 \% \mathrm{O}_{2}$ at $700^{\circ} \mathrm{C}$ for the first heat treatment $(\bullet)$ and $825^{\circ} \mathrm{C}$ for the second heat treatment (a). 